\title{
TREATMENT OF DEVELOPMENTAL DISLOCATION OF THE HIP IN CHILDREN AFTER WALKING AGE
}

\author{
INDICATIONS FROM TWO-DIRECTIONAL ARTHROGRAPHY
}

SHIGERU MITANI, YOICHI NAKATSUKA, HIROFUMI AKAZAWA, KIYOSHI AOKI, HAJIME INOUE

From Okayama University Medical School, Japan

We treated 120 children between the ages of 12 and 31 months with 137 developmental dislocations of the hip and reviewed them at a mean follow-up of 14 years.

We had used two-directional arthrography of all hips before reduction to evaluate the anterior, superior, and posterior portions of the limbus. Of the 137 hips, 64 had no interposed limbus in the AP view of the arthrogram, but 45 of these had an interposed anterior or posterior portion of the limbus. The hips with good stability and no interposed limbus in either AP or lateral arthrograms had excellent results by closed methods; in the other cases the results were less satisfactory.

Our findings suggest that hips suitable for management by closed reduction can be identified by two-directional arthrography. Hips shown to have an interposed limbus are best managed by open reduction.

J Bone Joint Surg [Br] 1997;79-B:710-8.

Received 28 February 1997; Accepted after revision 29 April 1997

The late presentation of developmental dislocation of the hip (DDH) is becoming less common because of neonatal screening and the introduction of sonography. Some abnormal hips still fail to respond to early conservative treatment and others are diagnosed after the patient has begun to walk. For these children, closed reduction is indicated only

S. Mitani, MD

Y. Nakatsuka, MD

H. Akazawa, MD

K. Aoki, MD

H. Inoue, MD

Department of Orthopaedic Surgery, Okayama University Medical School,

2-5-1 Shikata-cho, Okayama 700, Japan.

Correspondence should be sent to Dr S. Mitani.

C)1997 British Editorial Society of Bone and Joint Surgery 0301-620X/97/57728\$2.00 when a concentric and stable reduction of the hip can be obtained; the remainder will require an open procedure.

The quality of the reduction is usually assessed on an anteroposterior (AP) view of the arthrogram according to Miyake's classification, ${ }^{1}$ but many patients had poor results after closed reduction. Since 1973, we have used a lateral view of the arthrogram as well as an AP view to judge the accuracy of the reduction.

We investigated, retrospectively, the correlation between the information obtained from the two views and the results of treatment. We aimed to delineate more accurately the indications for closed reduction.

\section{PATIENTS AND METHODS}

From 1973 to 1995, we obtained two-directional arthrograms at the start of treatment from 174 patients aged between one and three years, with 197 complete dislocations of the hip. Children who had neuromuscular disease, chromosomal anomalies, septic arthritis, or recurrent dislocation were excluded.

We were able to review 137 hips in 120 of these patients at a mean length of follow-up of 14 years (10 to 21). There were 106 girls and 14 boys; their age at the time of arthrography is shown in Figure 1. Dislocation had been diagnosed in 66 hips after walking began, and in 71 hips conservative treatment had been unsuccessful.

Arthrography was performed under general anaesthesia. After attempted reduction an AP and a modified Dunlap's lateral view ${ }^{2}$ were taken (Fig. 2). To assess the AP radiograph we used Miyake's classification ${ }^{1}$ (Fig. 3) which defines types of limbus as follows: 'everted' which has a blunted and turned out appearance, 'intermediate' with a blunted and infolded shape causing minimal block to reduction, 'inverted' which is infolded and interposed between the femoral head and the acetabulum, 'blockaded' which prevents the entrance of dye into the true acetabulum and has an ill-defined shape and 'impossible' which obviously prevents reduction. Miyake recommended that only the everted and intermediate types should be treated by closed methods. We designated two groups as types CR, closed reduction, and $\mathrm{OR}$, open reduction. 


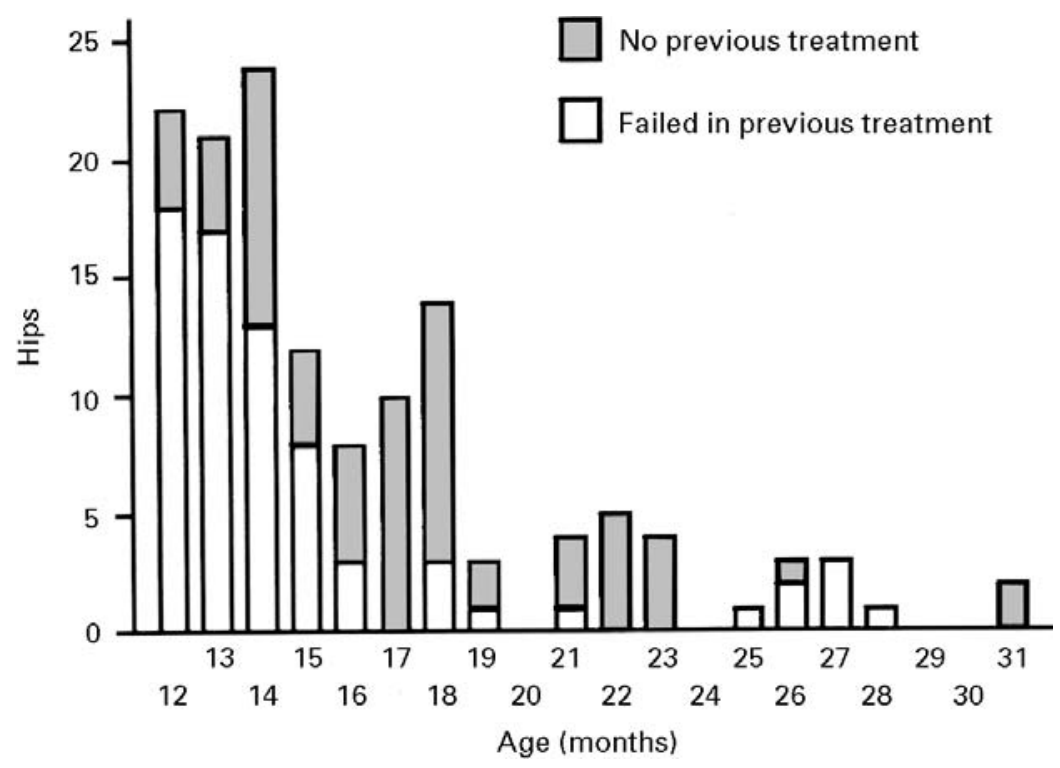

Fig. 1

Age distribution at the time of arthrography.

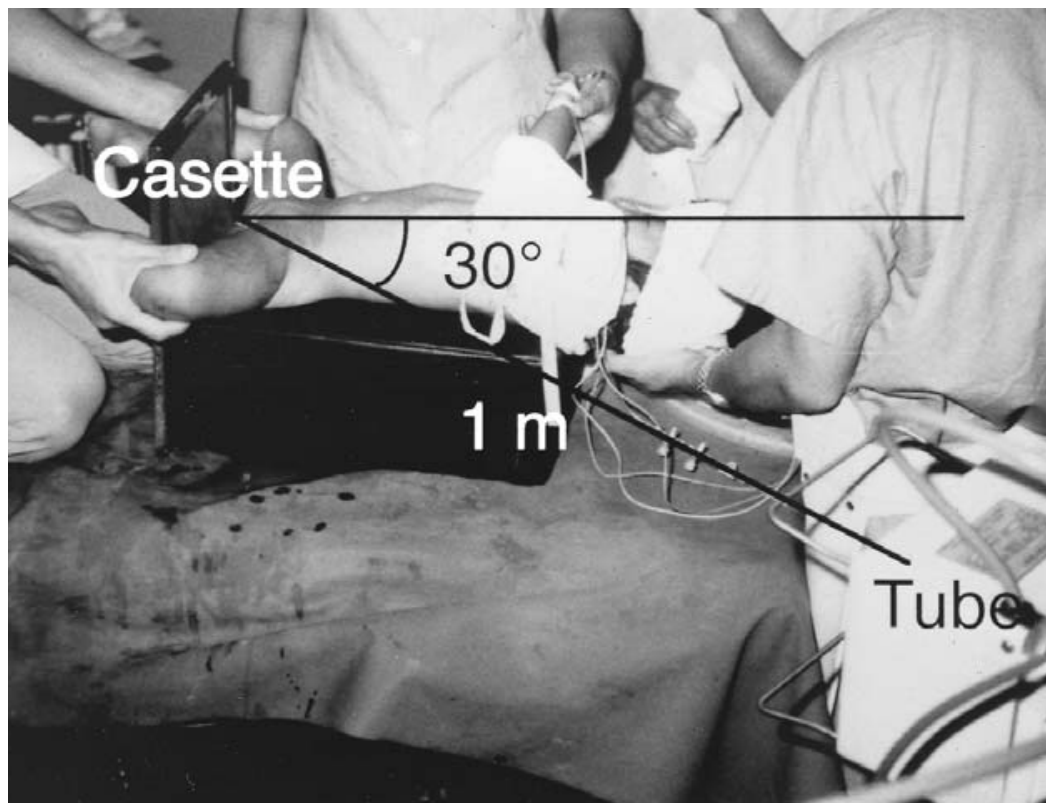

Fig. 2

Photograph showing an arthrogram being taken using a modified Dunlap's technique. The tube is tilted so that the beam forms an angle of $30^{\circ}$ with the long axis of the pelvis.

The supplementary lateral arthrogram has enabled us to visualise a tight iliopsoas, adhesions around the posterior capsule and inversion of a portion of the limbus (Fig. 4). The lateral views were divided into three types based on the relation of the limbus to the femoral head, and the shape of its anterior and posterior portions (Fig. 5). In type A, the head moves over the posterior limbus and the anterior limbus is not inverted. In type B, the head moves over the posterior limbus, but the anterior limbus is inverted and obstructs concentric reduction. In type $\mathrm{C}$, the femoral head will reduce anteriorly but the posterior limbus is infolded and interposed between the femoral head and the acetabulum.

At the final examination, radiological assessment of the anatomical results was carried out as described by Severin. ${ }^{3}$ Avascular necrosis (AVN) of the femoral head was classified according to Kalamchi and MacEwen. ${ }^{4}$

\section{RESULTS}

Of the 137 hips, 38 were classified as type CR and managed by closed reduction. Of these, 32 had had an initially successful closed reduction, but six redislocated while in the cast and required open reduction. No attempt at closed reduction was made in the other 99 hips classified as type OR. Open reduction was carried out through an anterolateral approach as described by Tanabe, Kunisada and Miyake $^{5}$ and Akazawa, Tanabe and Miyake. ${ }^{6}$ Further pro- 


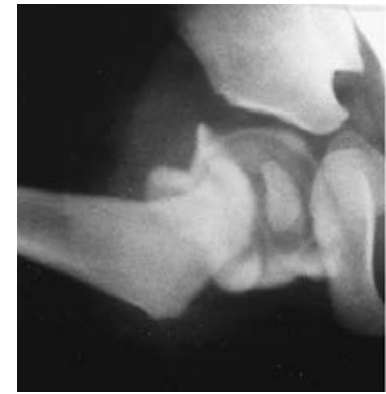

Fig. 3a

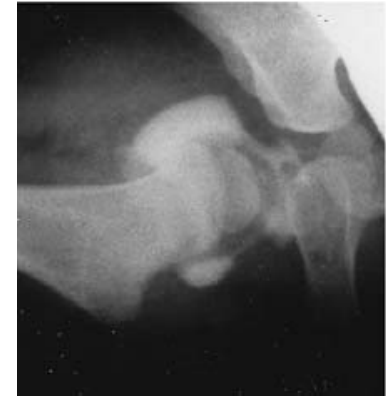

Fig. 3d

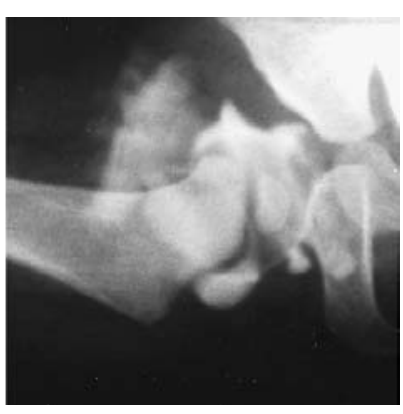

Fig. 3b

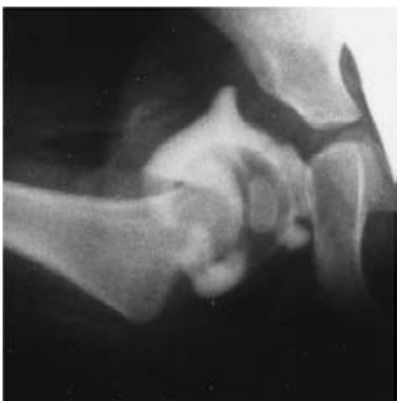

Fig. 3e

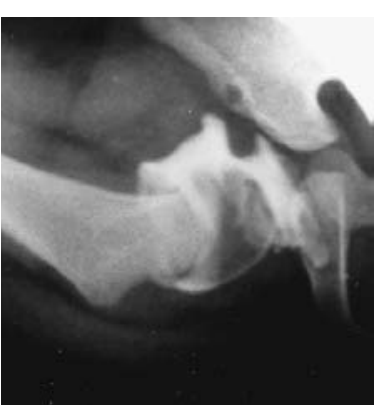

Fig. 3c

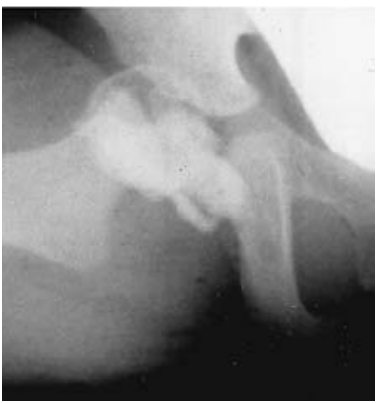

Fig. 3f

Illustration of Miyake's classification of the limbus showing a) normal, b) everted, c) intermediate, d) inverted, e) blockaded and f) impossible types. In our study, the everted and the intermediate types were designated as type CR and the others as type OR.
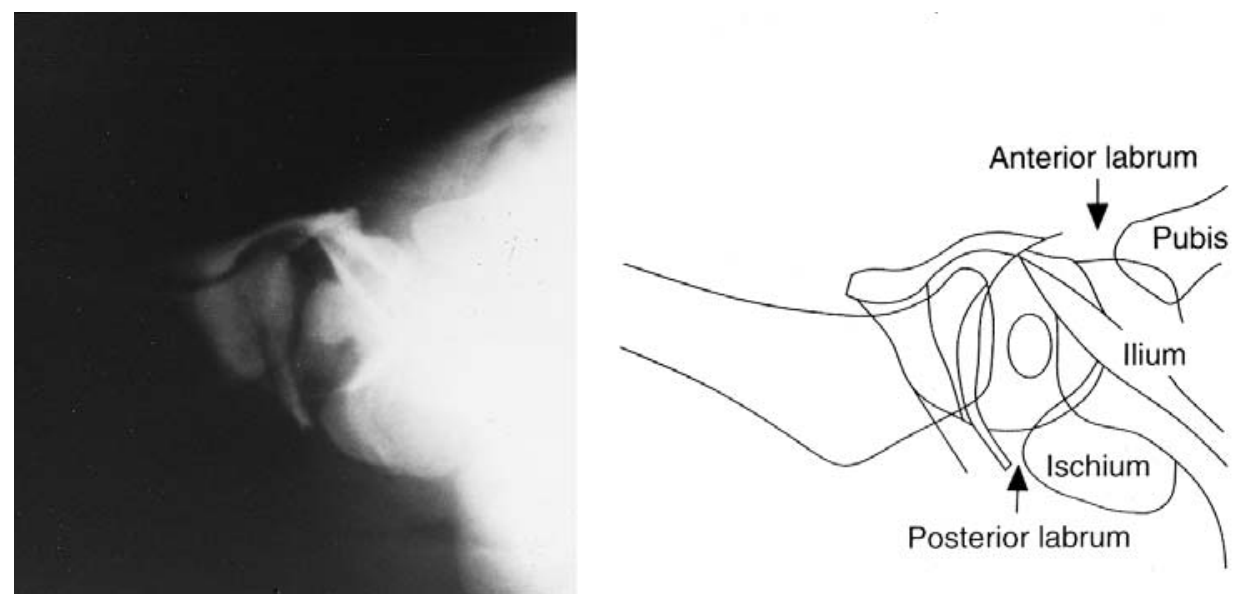

Fig. 4

Normal lateral view of the arthrogram to illustrate the structures visible. The anterior and posterior parts of the labrum can be clearly seen.

cedures were needed in 17 hips after reduction. Operations were a pelvic osteotomy in ten, a femoral varus derotation osteotomy in three, arthrotomy in three and a Colonna capsular arthroplasty in one.

The distribution of the arthrographic classification is shown in Table I. The superior portion of the limbus was not interposed in 65 hips (type CR); of these, 45 had an inverted anterior or posterior portion of the limbus which intervened between the femoral head and the acetabulum.
Of the CR cases, 17 hips were rated as type A on the lateral view, but of those in which previous treatment had failed only two had this appearance (Fisher's exact test: $p<0.01$ ). No patient over the age of two years was classified as CR with type A.

Of the 65 hips classified as type CR, 38 were concentrically reduced without forced abduction and had only a closed reduction. A stable reduction was achieved in all 19 hips classified as CR, with type A lateral, in 15 (45.5\%) of 


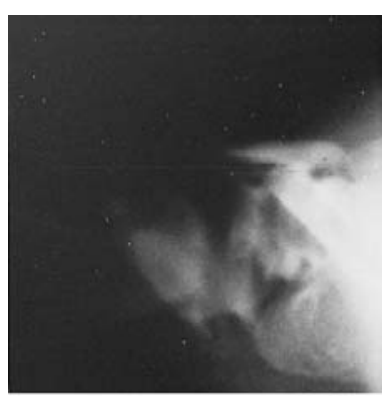

Fig. 5a

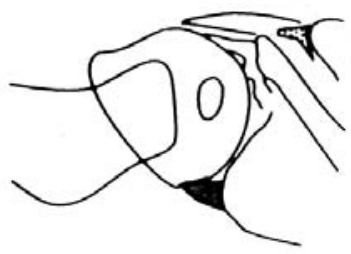

Fig. 5e

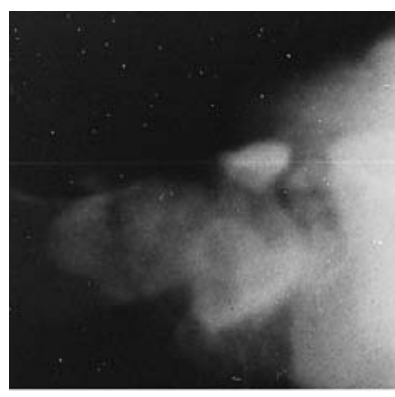

Fig. 5b

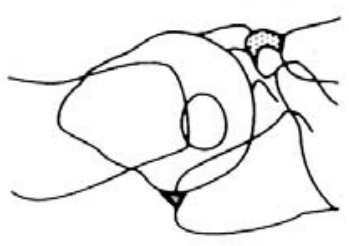

Fig. $5 f$

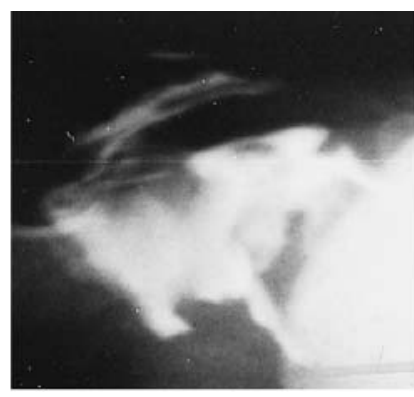

Fig. 5c

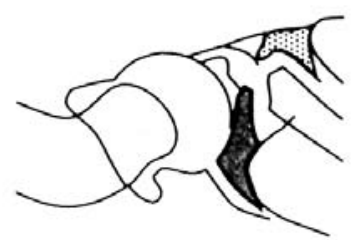

Fig. 5g

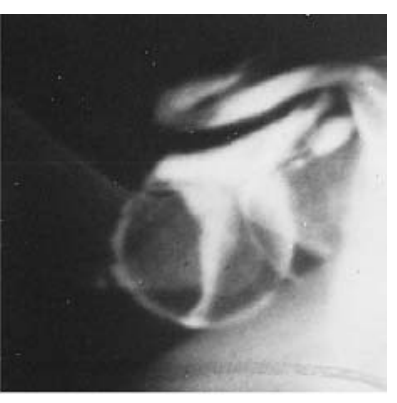

Fig. 5d

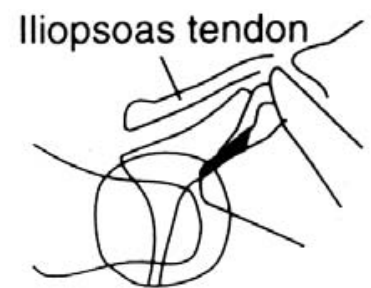

Fig. 5h

$\checkmark$ Anterior limbus

Posterior limbus

Structures seen on a lateral view of the arthrogram: a) e) type A; b) f) type B; c), d), g), h) type C.

33 CR hips with type B, and in four $(30.8 \%)$ of 13 CR hips with type C. Of these 38 hips, 32 had successful closed reduction, which was maintained. Six redislocated and had an open reduction; one was type $\mathrm{A}$, three type $\mathrm{B}$, and two type C. Of type A, 16 hips $(84.2 \%)$ achieved Severin group I without a supplementary operation, whereas only three of the $19(15.8 \%)$ type B or C attained this level (Table II).

Table I. Arthrographic classification

\begin{tabular}{lccc}
\hline Type & Type CR & Type OR & Total \\
\hline No previous treatment $(\mathrm{n}=67)$ & & \\
A & 17 & 6 & 17 \\
B & 19 & 18 & 25 \\
C & 7 & 24 & 25 \\
Total & 43 & & 67 \\
After failed treatment $(\mathrm{n}=70)$ & & \\
A & 2 & 20 & 2 \\
B & 14 & 28 & 34 \\
C & 6 & 48 & 70 \\
Total & 22 & & \\
\hline
\end{tabular}

The incidence of Severin group I or group II in type A was much higher than in type B or type C (Fisher's exact test: $\mathrm{p}<0.05)$.

Of 105 hips which had open reductions, $66(62.9 \%)$ achieved Severin group I (Table III). We found no significant correlation between the previous treatment and the results after this procedure. In CR hips with type B or C lateral views, the incidence of Severin group I or group II hips after open reduction was significantly greater than in those treated by closed reduction (Fisher's probability test: $\mathrm{p}<0.05$ ) (Table IV).

Nine hips had evidence of AVN of the femoral head before reduction. They all had failure of previous conservative treatment and were classified as OR with type B or $\mathrm{C}$ lateral views. AVN developed in five hips after closed reduction with grade- 2 changes in two and grade- 3 changes in three. In those classified as CR with type A only one (5.5\%) showed AVN, whereas there were five $(35.7 \%)$ in type B or type C. The incidence of AVN in hips classified as type $\mathrm{A}$ was significantly lower than in types $\mathrm{B}$ or $\mathrm{C}$

Table II. Radiological results in 38 hips after attempted closed reduction

\begin{tabular}{lrllllr}
\hline AG/Severin classification & \multicolumn{1}{c}{ I } & II & III & IV & Redislocation & Total \\
\hline Type CR with type A & 16 & $1(1)^{*}$ & 1 & & 1 & $19(1)$ \\
Type CR with type B & $5(2)$ & & $6(2)$ & 1 & 2 & $14(4)$ \\
Type CR with type C & $1(1)$ & & 1 & & 3 & $5(1)$ \\
Total & $22(3)$ & $1(1)$ & $8(2)$ & 1 & 6 & $38(6)$
\end{tabular}

* figures in parentheses represent supplementary operations 
Table III. Radiological results in 105 hips after open reduction

\begin{tabular}{llcclc}
\hline $\begin{array}{l}\text { Prev treatment/ } \\
\text { Severin class }\end{array}$ & I & II & III & IV & Total \\
\hline None & $21(2)^{*}$ & 4 & $7(2)$ & 2 & $34(4)$ \\
Failed & $45(2)$ & $12(1)$ & $11(3)$ & $3(1)$ & $71(7)$ \\
Total & $66(4)$ & $16(1)$ & $18(5)$ & $5(1)$ & $105(11)$ \\
\hline
\end{tabular}

* figures in parentheses represent supplementary operations

Table IV. Radiological results in 46 hips of type CR with type B or C

\begin{tabular}{lccccc}
\hline $\begin{array}{l}\text { Reduction/ } \\
\text { Severin classification }\end{array}$ & I & II & III & IV & Total \\
\hline Closed & $6(3)^{*}$ & & $7(2)$ & 1 & $14(5)$ \\
Open & $25(1)$ & 3 & 4 & 0 & $32(1)$ \\
Total & $31(4)$ & 3 & $11(2)$ & 1 & $46(6)$ \\
\hline
\end{tabular}

* figures in parentheses represent supplementary operations
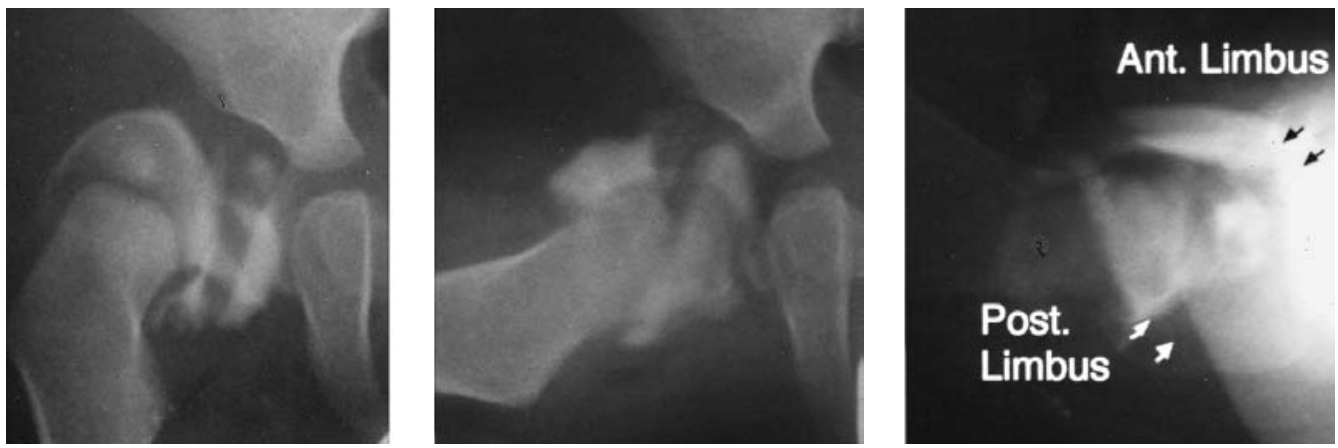

Fig. 6a
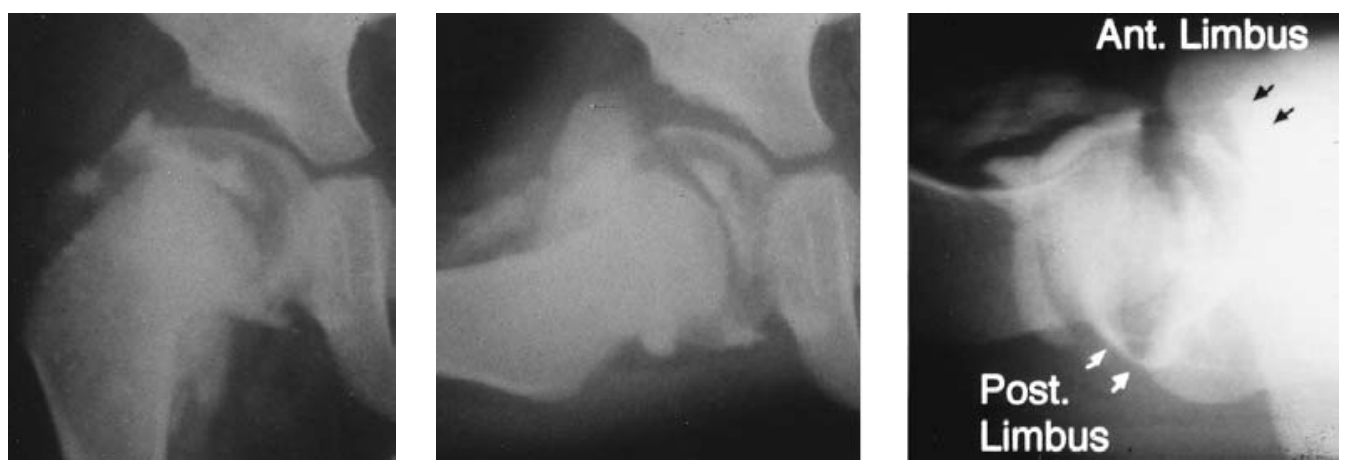

Fig. 6b

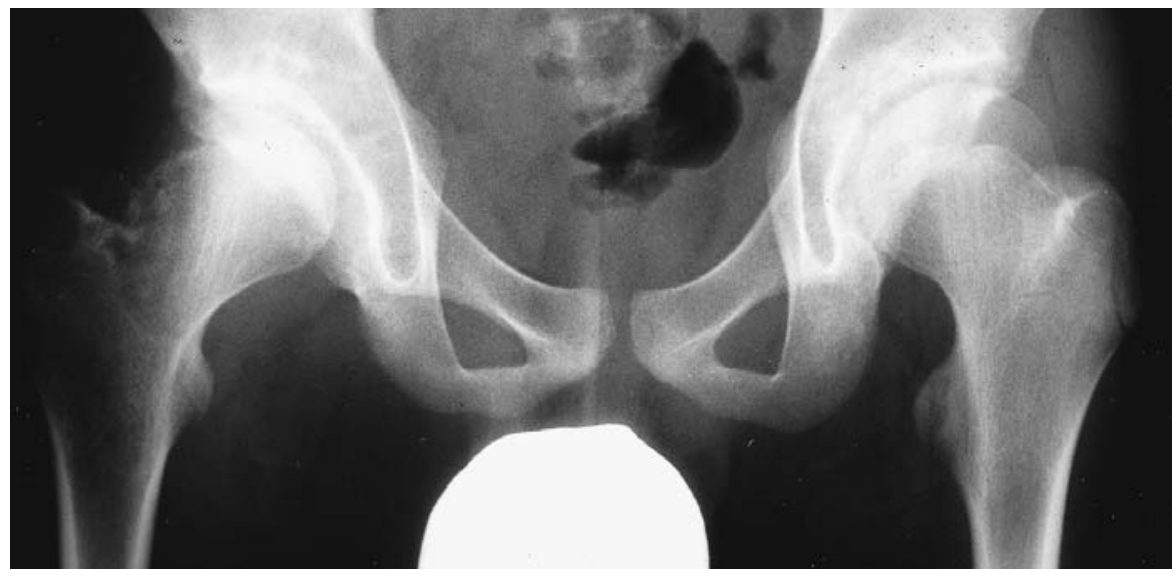

AP and lateral arthrograms of dislocation of the right hip in a 16-month-old boy.

Figure $6 \mathrm{a}-$ In the lateral view, an inverted anterior limbus obstructs concentric reduction (type B). Figure $6 \mathrm{~b}-$ After closed reduction, residual subluxation and AVN persisted. An arthrogram at the age of three years showed an inverted anterior limbus that was interposed like a meniscus. Salter innominate osteotomy was undertaken in an attempt to salvage the hip. Figure $6 c-$ At the age of 16 years his right hip was rated as Severin group III.

Fig. 6c 

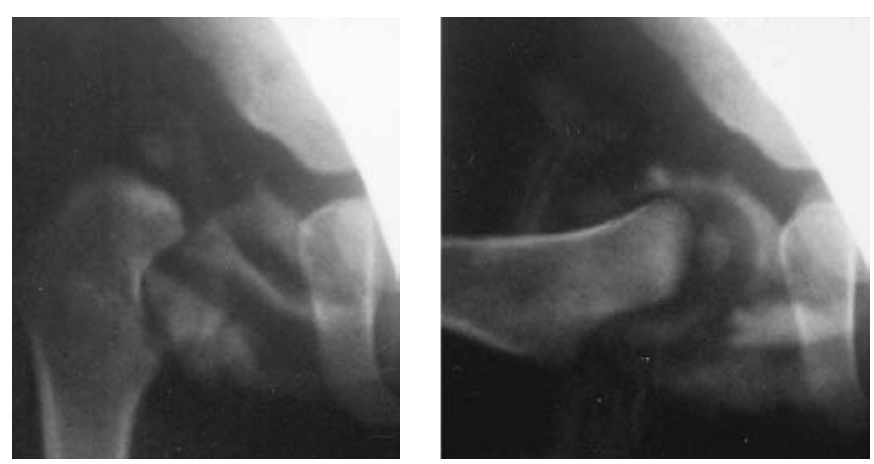

Fig. 7a
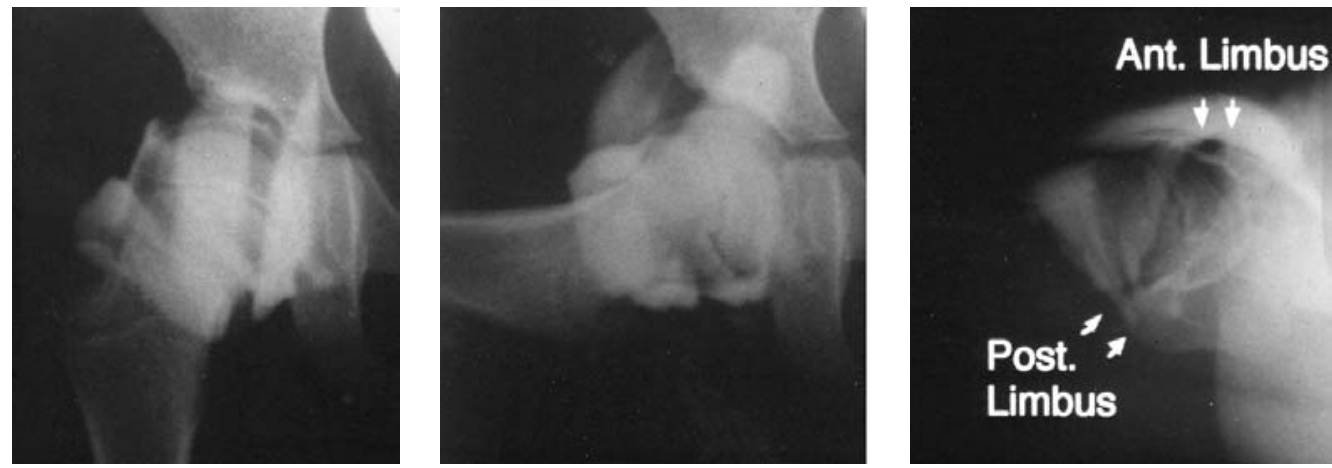

Fig. $7 b$

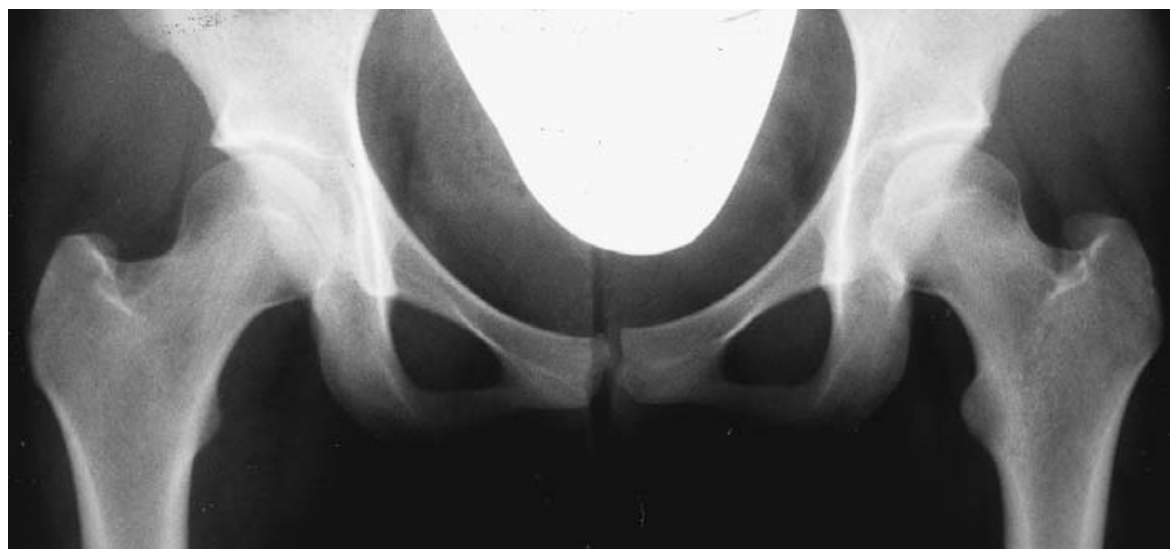

$\mathrm{AP}$ and lateral arthrograms of dislocation of the right hip in a 15-month-old girl.

Figure $7 \mathrm{a}-$ The lateral view shows that concentric reduction was not obtained. The anterior limbus was everted along with the femoral head (type A). Figure $7 \mathrm{~b}-\mathrm{AP}$ and lateral arthrograms at the age of six years showing the normal shape of the labrum. Figure $7 \mathrm{c}-$ At the age of 18 years her left hip was classified as Severin group Ia.

Fig. 7c

(Fisher's probability test: $\mathrm{p}<0.05)$. After open reduction, grade- 2 necrosis developed in 12 hips and grade 3 in four.

\section{DISCUSSION}

The aim of treatment in DDH is to obtain a congruous and concentric reduction with minimal risk of AVN. Children under one year of age can be managed by closed methods, but open reduction is necessary for those over the age of three years. Between these two ages a dislocated hip may be managed by closed reduction or by an operation which allows complete removal of all soft-tissue obstruction and a shorter immobilisation. Tonnis ${ }^{7}$ reported that the incidence of AVN of the femoral head was increased if open reduction was preceded by failed conservative treatment. In our patients AVN was already recognised in nine hips before operation and all had unsuccessful previous closed treatment. Repeated closed treatment should not be attempted for patients who have an increased risk of AVN or for recurrent dislocation even if manual 'reduction' is possible.

Ramsey, Lasser and MacEwen ${ }^{8}$ described the safe zone in the treatment of DDH. The most important factor determining the outcome of closed treatment is stability at reduction. Zionts and MacEwen ${ }^{9}$ recommended treatment 

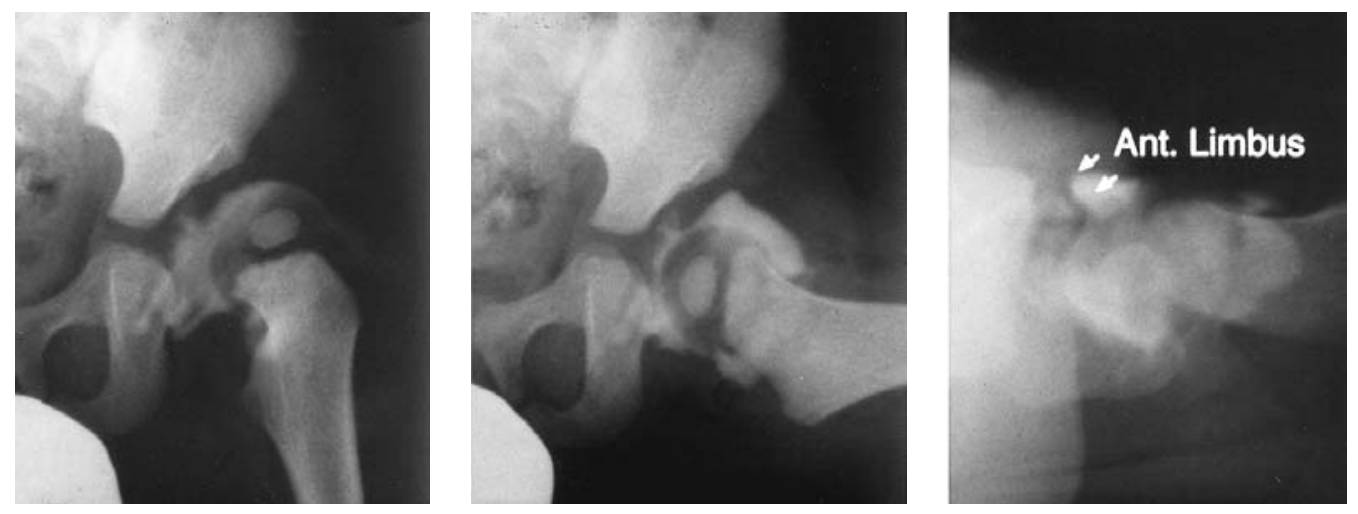

Fig. 8a

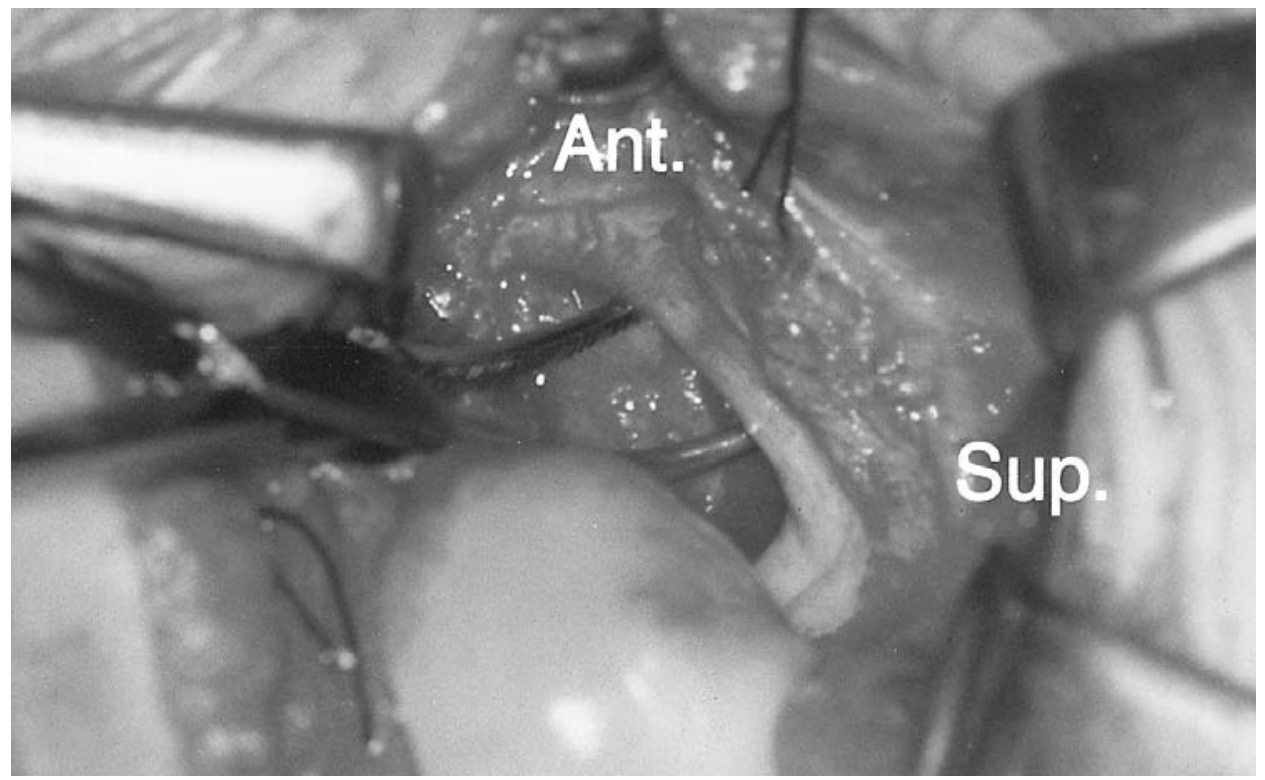

Fig. 8b

AP and lateral arthrograms in a 16-month-old boy with dislocation of the left hip that could not be reduced by Pavlik harness. Figure 8a - An inverted anterior limbus was seen in the lateral view (type B). Figure $8 \mathrm{~b}-\mathrm{He}$ had an open reduction without an attempted closed reduction. At operation, an inverted limbus was seen. It was shorter, tough and difficult to relocate.

according to the stability of the hip and undertook closed reduction in 38 of 51 patients with DDH aged between one and three years. They had good results with closed treatment, but 25 of the 38 hips required subsequent operation. Other authors have evaluated the quality of reduction from an AP view of an arthrogram alone. Race and Herring ${ }^{10}$ reported good results from conservative treatment in $62.5 \%$ of patients diagnosed before two years of age. Fleissner et $\mathrm{al}^{11}$ reported that 32 out of 42 children with DDH with a non-obstructive limbus in the AP view and an adequate cone of stability achieved a Severin group-I result. Berkeley et $\mathrm{al}^{12}$ performed closed reduction only for patients with good stability and no soft-tissue interposition. Almost all their patients required open reduction.

We agree that the indications for treatment should be based on the quality and stability of the initial reduction.
We found a significant correlation between stability and the shape of the limbus: all our hips rated in CR with type A lateral views had good stability. In some hips, however, with good stability and no interposed limbus in the AP view (type $\mathrm{CR}$ ), the anterior or posterior limbus obstructed a concentric reduction (type B and type $\mathrm{C}$ ). These patients, CR with type B or C (Fig. 6), had relatively poor results (Fig. 7). The results of open reduction for hips classified as $\mathrm{CR}$ with type $\mathrm{B}$ or type $\mathrm{C}$ lateral views were significantly better than after closed reduction. We no longer attempt closed reduction, except for $\mathrm{CR}$ hips with type-A lateral views.

Severin ${ }^{13}$ considered that soft-tissue structures obstructing concentric reduction would yield in time (his 'docking' theory). Lloyd-Roberts and Swann ${ }^{14}$ considered that this did not always happen and we agree with their view. 


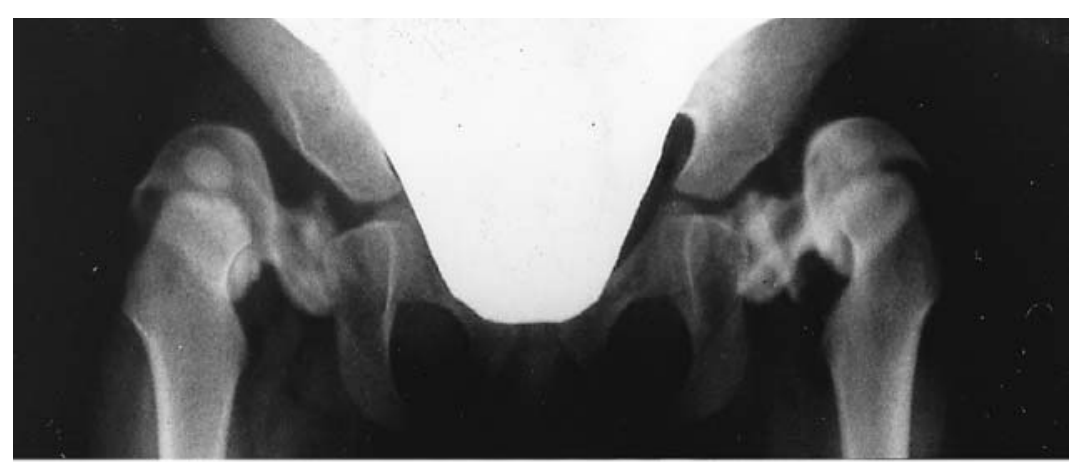

Fig. 9a

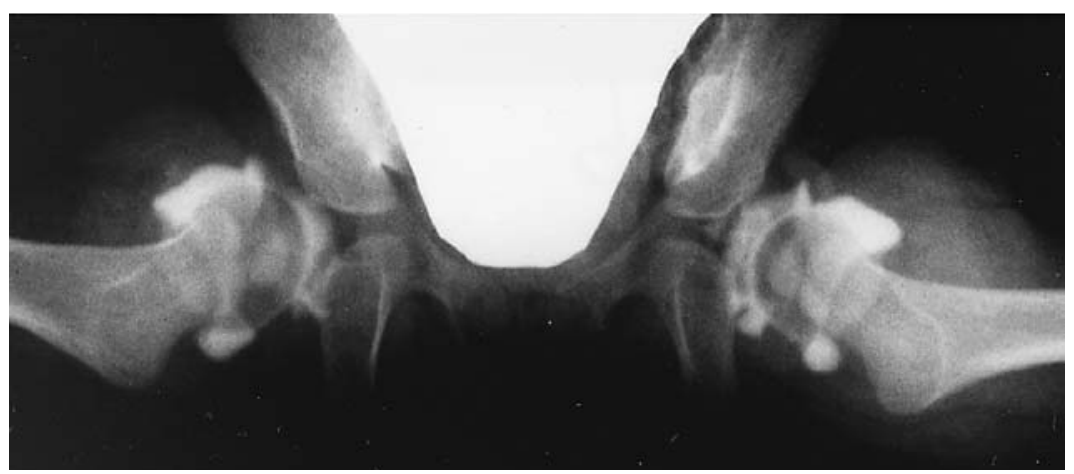

Fig. 9b

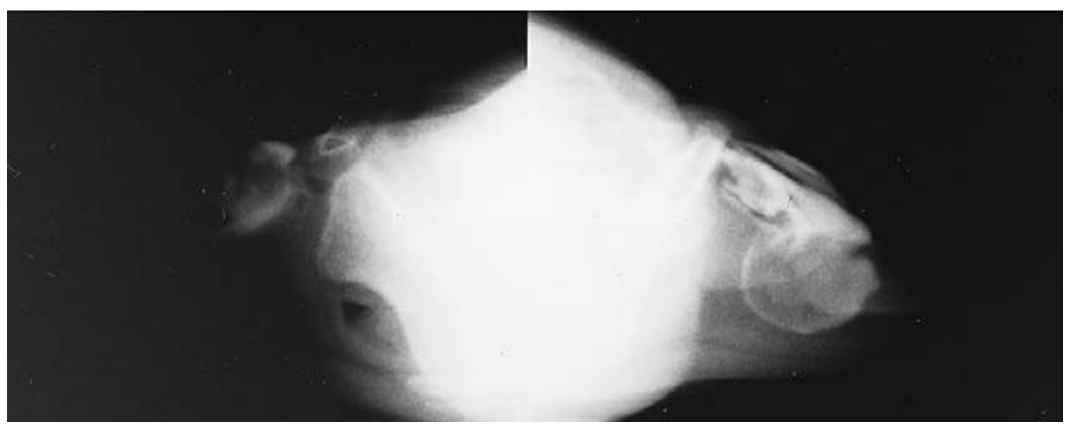

Fig. 9c

Bilateral dislocation of the hip in a 19-month-old girl. The AP arthrograms were similar in appearance $(\mathrm{a}, \mathrm{b})$ but in the lateral view the right hip was classified as type A and left hip as type $\mathrm{C}(\mathrm{c})$. Her right hip was treated with closed reduction and left hip with an open procedure.

Renshaw ${ }^{15}$ emphasised that inadequate reduction by closed methods results in failure, especially when an inverted limbus obstructs concentric reduction. We consider that an inverted limbus, especially the anterior part, will seldom evert after walking has begun (Figs 6 and 8). An AP arthrogram shows only the superior portion of the limbus and is insufficient to assess its overall state. In our series, only one of $18 \mathrm{CR}$ hips with type-A appearance developed AVN, whereas five of 14 hips with type B or type C did so. Gotoh and Ando ${ }^{16}$ suggested that from their experimental study that deformity of the femoral head was caused by soft-tissue intra-articular obstruction. Our results support their suggestion. Hips in which conservative treatment is being considered should have two-directional arthrography to allow better assessment of congruity and avoid deformity of the head.

Kidner ${ }^{17}$ noted that the adhesion around the posterior capsule prevented a concentric reduction of the femoral head and Ishii, Weinstein and Ponseti ${ }^{18}$ demonstrated that a tight iliopsoas tendon sometimes blocked congruous reduction. Lateral arthrography allows better visualisation of all soft-tissue abnormalities (Fig. 9), including the anterior and 
Table V. Advantages of $\mathrm{AP}$ and lateral arthrograms (O, visible; $\Delta$, sometimes visible; $\mathrm{X}$, invisible)

\begin{tabular}{lll}
\hline & \multicolumn{2}{l}{ Visible in arthrogram? } \\
\cline { 2 - 3 } Obstacles to reduction & AP view & Lateral view \\
\hline Tight iliopsoas tendon & $\mathrm{X}$ & $\Delta$ \\
Adhesion around the post capsule & $\mathrm{X}$ & $\mathrm{O}$ \\
Inversion of the limbus & & \\
$\quad$ Ant part & $\mathrm{X}$ & $\mathrm{O}$ \\
Sup part & $\mathrm{O}$ & $\mathrm{X}$ \\
Post part & $\mathrm{X}$ & $\mathrm{O}$ \\
Contracted transverse ligament & $\Delta$ & $\mathrm{X}$ \\
Hypertrophied ligamentum teres & $\mathrm{O}$ & $\Delta$ \\
Hypertrophied fibro-fatty pulvinar & $\mathrm{O}$ & $\Delta$ \\
\hline
\end{tabular}

posterior limbus, a tight iliopsoas tendon, and fibrous adhesions around the posterior capsule (Table V).

We conclude that:

1) AP and lateral arthrography allows better assessment of congruity at the time of closed reduction of DDH.

2) Children with a CR hip and type-A lateral appearance are best managed by conservative treatment. They can expect good long-term results with a low incidence of both AVN and late reconstruction.

3) Open reduction is indicated for $\mathrm{CR}$ with type $\mathrm{B}$ or $\mathrm{C}$ lateral views and for OR hips.

4) When previous treatment has failed, conservative reduction should be used only for CR hips with type A. All other types require open reduction.

5) Hips with any evidence of AVN should be treated only by open reduction.

6) Patients who present over the age of two years should not be considered for conservative treatment.

We wish to thank Mr A. Catterall of the Royal National Orthopaedic Hospital, Stanmore, England for help in the preparation of this manuscript.

No benefits in any form have been received or will be received from a commercial party related directly or indirectly to the subject of this article.

\section{REFERENCES}

1. Miyake Y. Evaluation of arthrogram of congenital dislocation of the hip: especially for the strangulation of ligamentum transversum acetabuli. Cent Jpn J Orthop Traumat 1967;10:467-83 (in Japanese).

2. Dunlap K, Swanson AB, Renner RS. Studies of the hip joint by means of lateral acetabular roentgenograms. J Bone Joint Surg [Am] 1956;38-A:1218-30.

3. Severin E. Contribution to knowledge of congenital dislocation of hip joint: late results of closed reduction and arthrographic studies of recent cases. Acta Chir Scand 1941 [Suppl 63];84;1-142.

4. Kalamchi A, MacEwen GD. Avascular necrosis following treatment of congenital dislocation of the hip. J Bone Joint Surg [Am] 1980; 62-A:876-88.

5. Tanabe G, Kunisada H, Miyake Y. A modified technique for open reduction of congenital dislocation of the hip. J Jpn Orthop Ass 1977; 51:503-11 (in Japanese).

6. Akawaza H, Tanabe G, Miyake Y. A new open reduction treatment for congenital hip dislocation: long-term follow-up of the extensive anterolateral approach. Acta Med Okayama 1990;44:223-31.

7. Tonnis D. Congenital hip dislocation. New York; Thieme-Stratton Inc, 1982.

8. Ramsey PL, Lasser S, MacEwen GD. Congenital dislocation of the hip: use of Pavlik harness in the child during the first six months of life. J Bone Joint Surg [Am] 1976;58-A:1000-4.

9. Zionts LE, MacEwen GD. Treatment of congenital dislocation of the hip in children between the ages of one and three years. J Bone Joint Surg [Am] 1986;68-A:829-46.

10. Race C, Herring JA. Congenital dislocation of the hip: an evaluation of closed reduction. J Pediatr Orthop 1983;3:166-72.

11. Fleissner PR, Ciccarelli CJ, Eilert RE, Chang FM, Glancy GL. The success of closed reduction in the treatment of complex developmental dislocation of the hip. J Pediatr Orthop 1994;14:631-5.

12. Berkeley ME, Dickson JH, Cain TE, Donovan MM. Surgical therapy for congenital dislocation of the hip in patients who are twelve to thirty-six months old. J Bone Joint Surg [Am] 1984;66-A:412-20.

13. Severin E. Congenital dislocation of the hip: development of the hip joint after closed reduction. J Bone Joint Surg [Am] 1950;32-A: 507-18.

14. Lloyd-Roberts G, Swann M. Pitfalls in the management of congenital dislocation of the hip. J Bone Joint Surg [Br] 1966;48-B:666-81.

15. Renshaw TS. Inadequate reduction of congenital dislocation of the hip. J Bone Joint Surg [Am] 1981;63-A:1114-21.

16. Gotoh H, Ando M. The pathogenesis of femoral head deformity in congenital dislocation of the hip: experimental study of the effects of articular interposition in pigs. Clin Orthop 1993;288:303-9.

17. Kidner FC. Open reduction of congenital dislocation of the hip. J Bone Joint Surg 1931;13:799-810.

18. Ishii Y, Weinstein SL, Ponseti IV. Correlation between arthrograms and operative findings in congenital dislocation of the hip. Clin Orthop 1980;153:138-45. 